\title{
STUDI DESKRIPTIF GAYA EKSPLANATORI ANAK PENDERITA LEUKEMIA
}

\author{
Anna Maria Amanda Putri, Sianiwati Sunarto Hidayat, Eveline Sarintohe \\ Universitas Kristen Maranatha \\ amandatjan7892@gmail.com, sianiwati.sh@psy.maranatha.edu, \\ eveline.sarintohe@psy.maranatha.edu
}

\begin{abstract}
This descriptive research conducted with 25 children under purposive sampling to obtain an overview of expanatory style of children with leukemia in the Foundation " $X$ " Bandung. Measurement instrument is a modification of the Children's Attributional Style Questionnaire (CASQ) by Seligman (1990) which consists of 48 items forced choice. Explanatory style research showed that $60 \%$ respondents have a pessimistic, and the rest have an optimistic. There is a link between children's understanding of their significant person's explanatory style, criticism from parents or the trustees, their crisis experience, as well as the stage of suffering from leukemia with the children with leukemia's explanatory style. This research suggested further research with more sample sizes about children's explanatory style in order to make normative constraints, also further investigate the factors that affect explanatory style and dimensions. It is also suggested that management of the Foundation " $X$ " to design interventions that can improve children's explanatory style.
\end{abstract}

Key terms: explanatory style, leukemia

\begin{abstract}
Abstrak
Penelitian ini dilakukan untuk memperoleh gambaran mengenai gaya eksplanatori pada anak penderita leukemia di Yayasan " $\mathrm{X}$ " Kota Bandung. Pemilihan sampel menggunakan purposive sampling, dan sampel dalam penelitian ini berjumlah 25 anak. Penelitian ini adalah penelitian deskriptif. Alat ukur yang digunakan merupakan modifikasi dari Children's Attributional Style Questionnaire (CASQ) dari Seligman (1990) dan terdiri dari 48 item yang bersifat forced choice. Data hasil penelitian diolah secara deskriptif. Sebanyak 60\% responden memiliki gaya eksplanatori pesimis, dan $40 \%$ responden lainnya memiliki gaya eksplanatori optimis. Terdapat kaitan antara pemahaman anak mengenai orang penting seputar gaya eksplanatori, kritik dari orangtua atau pengurus yayasan, krisis yang dialami, serta stadium anak penderita leukemia dengan gaya eksplanatori yang dimilikinya. Berdasarkan penelitian ini, disarankan bagi peneliti selanjutnya untuk melakukan penelitian dengan jumlah sampel lebih banyak agar dapat membuat batasan normatif, juga meneliti lebih lanjut mengenai faktor yang memengaruhi gaya eksplanatori dan dimensinya dan bagi pengurus Yayasan " $\mathrm{X}$ ", untuk merancang intervensi yang dapat meningkatkan gaya eksplanatori.
\end{abstract}

Kata kunci: gaya eksplanatori, anak penderita leukemia 


\section{PENDAHULUAN}

Kesehatan merupakan hal yang penting bagi manusia, namun tidak semua orang dapat menikmati hidup yang sehat. Kini banyak hal dapat mengancam kesehatan manusia, salah satunya adalah kanker. Kanker menjadi salah satu masalah kesehatan masyarakat, baik di dunia maupun di Indonesia. Tingginya kematian akibat kanker menjadi momok bagi masalah kesehatan. Hal tersebut didukung dengan pernyataan dari Andhika Rachman, ahli hematology dan oncology dari Rumah Sakit Kanker Dharmais menyatakan bahwa kanker dapat terjadi pada seluruh organ tubuh dan dapat dialami siapa saja, tidak terkecuali anakanak.

Pada anak, penyebab kematian kedua tertinggi adalah kanker (US Mortality Data, 2006). Leukemia merupakan jenis kanker yang paling sering terjadi pada anak dan menempati 30\% dari seluruh kanker yang terjadi pada anak (Rofinda, 2013). Menurut Prof. Dr. Sutaryo dalam pembukaan International Confederation of Childhood Cancer Parent Organizations di Yogyakarta pada 22 April 2012, sebanyak 90\% anak yang menderita leukemia dapat disembuhkan jika mereka dengan segera mendapatkan pengobatan yang dibutuhkan. Hal yang menjadi kendala bagi penderita leukemia untuk mendapatkan kesembuhan adalah tingginya biaya pengobatan (Achmad, 2013). Hal tersebut menimbulkan kepedulian berbagai pihak, salah satunya dengan didirikannya yayasan kanker, yang umumnya bersifat nirlaba.

Yayasan " $\mathrm{X}$ " adalah salah satu yayasan kanker dengan fokus penanganan pada anak yang menderita kanker dengan status sosial ekonomi menengah ke bawah. Yayasan " $X$ " memiliki misi untuk memberikan informasi kepada masyarakat awam dalam menangani kanker, serta menyediakan rumah singgah, transportasi dan fasilitas pendidikan bagi anak-anak yang sedang berada dalam pengobatan dan perawatan di rumah sakit. Fasilitas yang terdapat di Yayasan " $X$ " Kota Bandung berupa tempat tinggal termasuk fasilitas kamar tidur, makan 3 kali dalam sehari, dan layanan pendidikan bagi anak yang menderita kanker, kemudahan untuk akses ke rumah sakit, dan obat-obatan bagi anak yang menderita kanker.

Bantuan yang diberikan oleh Yayasan " $X$ " bagi anak yang menderita leukemia membuat anak memiliki harapan hidup yang lebih tinggi. Dengan berada di Yayasan " $X$ " anak yang menderita leukemia tidak begitu saja terlepas dari penyakit yang mereka derita. Berbagai situasi yang dialami anak yang menderita leukemia di Yayasan " $X$ " Kota Bandung akan menimbulkan dampak bagi mereka, salah satunya terkait dengan cara pandangnya terhadap kehidupan. Suatu kebiasaan berpikir yang dimiliki individu dalam memandang kehidupan, baik dalam keadaan baik (good situation) maupun keadaan buruk (bad situation) dikenal dengan gaya eksplanatori (explanatory style) (Seligman, 2006). Gaya eksplanatori yang 
dimiliki individu berbeda-beda, terdapat individu yang memiliki gaya eksplanatori pesimis, ada pula individu yang memiliki gaya eksplanatori optimis (Seligman, 2006).

Seligman (2006) mengungkapkan bahwa individu yang memiliki gaya eksplanatori pesimis lebih mudah untuk menyerah dan lebih sering mengalami depresi, sedangkan individu yang memiliki gaya eksplanatori optimis memiliki kesehatan yang lebih baik. Oleh sebab itu, salah satu hal yang harus dimiliki oleh anak yang menderita leukemia di Yayasan "X" Kota Bandung untuk menghadapi kesulitan (adversity) tersebut adalah gaya eksplanatori optimistik. Dengan memiliki gaya eksplanatori optimis, anak yang menderita leukemia di Yayasan "X" Kota Bandung diharapkan dapat bertahan saat menghadapi masa sulit dalam menjalani hidupnya dengan tetap memiliki harapan akan hal yang lebih baik. Keyakinan dan harapan yang dimiliki anak yang menderita leukemia di Yayasan "X" Kota Bandung dapat membuat mereka bangkit dan melanjutkan hidup.

\section{METODE}

Penelitian ini menggunakan metode deskriptif dan dilengkapi dengan data hasil wawancara. Alat ukur yang dipakai adalah kuesioner untuk mengetahui gaya eksplanatori pada anak yang menderita leukemia di Yayasan " $X$ " Kota Bandung. Populasi sasaran dalam penelitian ini adalah anak yang menderita leukemia yang bergabung di Yayasan " $X$ " Kota Bandung, dengan usia antara 7 tahun sampai 11 tahun. Hasil penelitian ini diolah dengan menggunakan analisis deskriptif kuantitatif dan disajikan dalam bentuk distribusi frekuensi. Hasil perhitungan persentase derajat gaya eksplanatori kemudian digunakan untuk menarik simpulan sehingga dapat memberikan paparan mengenai derajat gaya eksplanatori anak yang menderita leukemia di Yayasan "X" Kota Bandung.

\section{HASIL}

Berdasarkan hasil pengolahan data, diketahui bahwa $60 \%$ dari partisipan penderita leukemia memiliki gaya eksplanatori pesimis. Anak yang memiliki gaya eksplanatori pesimis memandang bahwa keadaan buruk bersifat permanen dan ketika menghadapi keadaan baik, mereka memandang bahwa keadaan baik hanya bersifat sementara (Seligman, 2006). 53,3\% dari partisipan yang pesimis, memandang bahwa keadaan baik bersifat sementara. Sementara 
itu seluruh anak penderita leukemia baik dengan gaya eksplanatori pesimistis maupun optimis memandang bahwa keadaan buruk bersifat permanen. Sisanya, $40 \%$ partisipan penderita leukemia memiliki gaya eksplanatori optimistis. Sebagian besar dari mereka (36\%) memandang bahwa keadaan baik bersifat permanen dan semua partisipan anak penderita leukemia yang optimis memandang bahwa keadaan buruk bersifat permanen.

Tabel 1

Kontingensi Distribusi Frekuensi Gaya Eksplanatori dan Permanensi

\begin{tabular}{lccccc}
\hline \multirow{2}{*}{$\begin{array}{c}\text { Gaya } \\
\text { Eksplanatori }\end{array}$} & \multirow{2}{*}{ Total } & \multicolumn{2}{c}{ Baik } & \multicolumn{2}{c}{ Buruk } \\
\cline { 2 - 6 } & & Permanen & Temporer & Permanen & Temporer \\
\cline { 2 - 6 } & $\%$ & $\%$ & $\%$ & $\%$ & $\%$ \\
\hline Optimistic & 40 & 36 & 4 & 40 & 0 \\
\hline Pessimistic & 60 & 28 & 32 & 60 & 0 \\
\hline & 100 & 64 & 36 & 100 & 0 \\
\hline
\end{tabular}

Tabel 2

Kontingensi Distribusi Frekuensi Gaya Eksplanatori dan Pervasivenes

\begin{tabular}{cccccc}
\hline \multirow{2}{*}{$\begin{array}{c}\text { Gaya } \\
\text { Eksplanatori }\end{array}$} & \multirow{2}{*}{ Total } & \multicolumn{2}{c}{ Baik } & \multicolumn{2}{c}{ Buruk } \\
\cline { 2 - 6 } & $\%$ & Universal & Spesifik & Universal & Spesifik \\
\hline Optimistis & 40 & 28 & 12 & 0 & $\%$ \\
\hline Pesimistis & 60 & 4 & 56 & 8 & 52 \\
\hline Total & 100 & 32 & 68 & 8 & 92 \\
\hline
\end{tabular}

Tabel 3

Kontingensi Gaya Eksplanatori dengan Personalisasi

\begin{tabular}{cccccc}
\hline \multirow{2}{*}{$\begin{array}{c}\text { Gaya } \\
\text { Eksplanatori }\end{array}$} & \multirow{2}{*}{ Total } & \multicolumn{2}{c}{ Baik } & \multicolumn{2}{c}{ Buruk } \\
\cline { 2 - 6 } & & Internal & Eksternal & Internal & Eksternal \\
\cline { 2 - 6 } & $\%$ & $\%$ & $\%$ & $\%$ & $\%$ \\
\hline Optimistis & 40 & 32 & 8 & 8 & 32 \\
\hline Pesimistis & 60 & 12 & 48 & 36 & 24 \\
\hline Total & 100 & 44 & 56 & 44 & 56 \\
\hline
\end{tabular}

Berdasarkan tabel 2, sebesar 56\% dari partisipan penderita leukemia memiliki gaya eksplanatori pesimistis dan memandang bahwa keadaan baik yang dialaminya bersifat spesifik, berbanding empat persen yang memandang bahwa keadaan baik bersifat universal. 
Sebanyak 28\% partisipan memiliki gaya eksplanatori optimistis dan memandang bahwa keadaan baik yang dialaminya bersifat universal. Sebaliknya, keadaan buruk dianggap oleh mereka semua yang optimis (40\%) sebagai kondisi yang spesifik. Dari hasil tersebut bisa dilihat bahwa partisipan yang pesimis cenderung memandang keadaan baik itu spesifik dan keadaaan buruk bersifat universal. Sebaliknya, partisipan yang optimis cenderung menganggap bahwa keadaan baik itu bersifat universal atau terjadi di banyak bidang kehidupan dan menganggap keadaan buruk itu hanya terjadi pada bidang tertentu saja dalam hidupnya.

Berdasarkan tabel 3, partisipan yang optimis cenderung memandang bahwa peristiwa baik disebabkan oleh diri sendiri sementara keadaan buruk disebabkan oleh di luar dirinya. Sebaliknya partisipan yang pesimis, cenderung melihat peristiwa baik yang mereka alami adalah disebabkan oleh di luar diri mereka dan peristiwa buruk disebabkan oleh dalam diri mereka. Sebanyak 52,9\% anak yang menghayati significant person dalam memandang suatu keadaan baik (good situation) yang dihadapi adalah sesuatu yang menetap, menyeluruh, dan disebabkan oleh diri mereka sendiri (PmG-Permanent, PvG-Universal, PsG-Internal) memiliki gaya eksplanatori optimis.

Hasil pengolahan data menunjukkan perbedaan persentase yang mencolok, bahwa 87,5\% anak yang menghayati significant person dalam memandang suatu keadaan baik (good situation) adalah sesuatu yang bersifat sementara, terbatas pada bidang kehidupan tertentu saja, dan disebabkan oleh pihak lain (PmG-Temporary, PvG-Spesifik, PsG-External) memiliki gaya eksplanatori pesimistis. Sebanyak 55,6\% anak yang menghayati significant person dalam memandang suatu keadaan buruk (bad situation) adalah sesuatu yang bersifat sementara, terbatas pada bidang kehidupan tertentu saja, dan disebabkan oleh pihak lain (PmB-Temporary, PvB-Spesifik, PsB-Eksternal) memiliki gaya eksplanatori optimistis.

Seluruh (100\%) anak yang menghayati bahwa kritik yang mereka terima bersifat menetap dan menyeluruh di semua bidang kehidupan (PmB-Permanent, PvB-Universal) memiliki gaya eksplanatori pesimistis. Disamping itu, sebanyak 56,2\% anak yang menghayati bahwa kritik yang mereka terima bersifat sementara dan terbatas pada bidang tertentu saja (PmBTemporary, PvB-Spesifik) memiliki gaya eksplanatori optimistis. Begitu pula ketika menghadapi keadaan buruk, seluruh partisipan menghayati orang penting dalam memandang suatu keadaan buruk adalah sesuatu yang menetap, menyeluruh, dan disebabkan oleh diri mereka sendiri (PmB-Permanent, PvB-Universal, PsB-Internal) memiliki gaya eksplanatori pesimistis. Hal tersebut menunjukkan perbedaan hasil yang mencolok dan sejalan dengan teori Seligman (2006) bahwa anak cenderung meniru orang penting dalam hidupnya dalam menggunakan gaya eksplanatori. 


\section{PEMBAHASAN}

Menurut Seligman (2006), terdapat tiga dimensi dalam gaya eksplanatori yaitu permanensi, ruang lingkup (pervasiveness), dan personalisasi. Dimensi permanensi merupakan persepsi individu mengenai jangka waktu berlangsungnya suatu keadaan yang dihadapi. Dimensi ini berkaitan dengan waktu, yaitu apakah suatu kejadian bersifat permanen atau sementara. Hasil penelitian menunjukkan bahwa individu dengan gaya eksplanori pesimistis cenderung menganggap bahwa peristiwa buruk yang dialaminya adalah peristiwa yang permanen. Hal ini sejalan dengan pendapat Seligman (2006), bahwa individu dengan gaya eksplanatori pesimistis akan memandang keadaan buruk yang dialaminya sebagai sesuatu yang bersifat permanen. Menariknya, hasil penelitian menunjukkan bahwa individu dengan gaya eksplanori optimistis juga cenderung menganggap bahwa peristiwa buruk yang dialaminya merupakan peristiwa yang permanen. Tentu saja hasil ini bertentangan dengan pendapat Seligman (2006) yang mengatakan bahwa orang yang optimis akan cenderung menganggap bahwa peristiwa yang buruk adalah peristiwa yang bersifat sementara.

Sementara itu, hasil penelitian menunjukkan bahwa anak penderita leukimia yang pesimistis cenderung memandang bahwa peristiwa baik akan terjadi sementara saja sedangkan anak yang optimis cenderung memandang bahwa peristiwa baik adalah peristiwa yang akan terjadi terus menerus atau permanen. Hasil ini sejalan dengan pendapat Seligman (2006), yaitu individu yang memiliki gaya eksplanatori pesimistis memandang bahwa keadaan baik akan bersifat sementara dan individu yang memiliki gaya eksplanatori optimistis memandang bahwa keadaan baik bersifat permanen.

Dimensi kedua adalah ruang lingkup, merupakan persepsi individu mengenai ruang lingkup dari suatu keadaan yang dihadapi, yaitu universal atau spesifik (Seligman, 2006). Terdapat indikasi bahwa anak yang menderita leukemia cenderung memiliki cara pandang terhadap keadaan buruk sebagai sesuatu yang bersifat spesifik karena cara pikir anak yang menderita leukemia bersifat konkret operasional, sehingga pola pemikiran mereka terbatas pada situasi spesifik yang mereka alami.

Menurut Seligman (2006), individu yang memiliki gaya eksplanatori optimistis memiliki penjelasan universal ketika menghadapi keadaan baik. Hasil penelitian menunjukkan kesesuaian dengan teorinya bahwa bahwa anak yang menderita leukemia dengan gaya eksplanatori optimistis cenderung memandang bahwa keadaan baik bersifat universal atau bahwa hal baik terjadi pada banyak aspek kehidupannya. Selain itu, jika menghadapi kondisi buruk maka mereka menganggap bahwa yang dialaminya bersifat spesifik. 
Dimensi ketiga adalah personalisasi, yaitu persepsi individu mengenai siapa atau pihak mana yang menjadi penyebab dari suatu keadaan yang dihadapi. Individu yang memiliki gaya eksplanatori optimistis menganggap penyebab dari keadaan baik adalah dirinya sendiri (internal) (Seligman, 2006). Seligman (2006) mengatakan bahwa orang yang optimis mempersepsikan pihak yang menjadi penyebab keadaan baik adalah dirinya sendiri sementara penyebab keadaan buruk adalah pihak luar.

Pembentukan gaya eksplanatori seseorang dipengaruhi oleh tiga faktor, yaitu gaya eksplanatorisignificant person (orang sekitarnya yang sangat berpengaruh bagi dirinya), kritik orang dewasa, dan krisis yang dialami pada masa kanak-kanak (Seligman, 2006). Menurut Seligman (2006), anak melihat cara orang yang dianggapnya penting bagi dirinya atau berpengaruh terhadap dirinya dalam memandang suatu situasi lalu anak mengadopsi gaya eksplanatori itu melalui proses modeling atau meniru. Namun hasil pengolahan data dengan menunjukkan perbedaan persentase yang tidak mencolok. Hal ini dapat terjadi karena leukemia yang dialami oleh anak pada umumnya berada pada stadium IV, sehingga anak kurang mampu menghayati cara pandang significant person dalam menghadapi keadaan baik yang dialaminya.

Faktor kedua adalah kritik orang dewasa (Seligman, 2006). Kritik yang dilontarkan orangtua dan pengurus yayasan memiliki kaitan dengan gaya eksplanatori anak yang menderita leukemia. Keseusian hasil pengolahan data dengan teori Seligman tidak ditunjang dengan perbedaan persentase yang mencolok. Hal ini dapat terjadi karena anak yang menderita leukemia memiliki pola pemikiran konkret operasional, sehingga anak menghayati kritik yang diterimanya sebagai keadaan terjadi pada saat itu saja dan tidak menggeneralisasi gaya eksplanatori anak.

Faktor ketiga adalah krisis pada masa awal anak-anak (Seligman, 2006). Sejalan dengan teori yang dikemukakan oleh Seligman, didapatkan data bahwa seluruh (100\%) anak yang mengembangkan kebiasaan berpikir bahwa krisis yang dialaminya tersebut bersifat menetap, menyeluruh di semua bidang kehidupan, dan disebabkan oleh diri mereka sendiri (PmBPermanent, PvB-Universal, PsB-Internal) memiliki gaya eksplanatori pesismistis.

Sebagian besar partisipan anak yang menderita leukemia memiliki gaya eksplonatori pesimistis. Mayoritas mereka yang memiliki gaya eksplonatori pesimistis memandang bahwa keadaan baik yang dialaminya bersifat sementara, spesifik, dan eksternal. Namun ketika memandang keadaan buruk mayoritas anak yang menderita leukemia memandang bahwa keadaan yang dialaminya bersifat permanen, universal, dan internal. Mayoritas partisipan yang menderita leukemia dengan gaya eksplanatori optimis memandang bahwa keadaan baik yang dialaminya bersifat permanen, universal, dan internal. Ketika memandang keadaan 
buruk mayoritas anak yang menderita leukemia memandang bahwa keadaan yang dialaminya bersifat sementara, spesifik, dan external.

Pemahaman para partisipan terhadap gaya eksplanatori ibu memiliki kaitan dengan gaya eksplanatori mereka. Kritik dari orangtua atau pengurus yayasan, serta krisis yang dialami anak memiliki kaitan dengan gaya eksplanatori anak yang menderita leukemia. Selain itu waktu menderita dan stadium leukemia yang dialami anak juga menunjukkan kaitan dengan gaya eksplanatori anak. Bagi peneliti selanjutnya dapat melakukan penelitian dengan jumlah sampel lebih banyak mengenai gaya eksplanatori anak agar dapat membuat batasan normatif dalam menentukan kriteria penggolongan pada setiap dimensi, sehingga dapat mengetahui dimensi mana yang perlu ditingkatkan. Selain itu dapat melakukan penelitian kualitatif mengenai faktor yang memengaruhi gaya eksplanatori dan dimensinya sehingga mendapatkan gambaran yang mendalam.

Bagi para pengurus dan pengajar Yayasan sebaiknya mengetahui gambaran umum gaya eksplanatori anak penderita leukemia yang tinggal di yayasan sehingga dapat merancang intervensi bagi mereka agar mampu memandang keadaan baik dan keadaan buruk secara lebih tepat, sehingga anak memiliki gaya eksplanatori optimistis. Selain itu dapat memberikan pendampingan yang intensif terhadap anak penderita leukemia yang menderita kurang dari 1 tahun, serta terhadap anak yang menderita leukemia dengan stadium III dan IV. Bagi orangtua dari anak, mengubah gaya eksplanatori mereka menjadi optimistis adalah salah satu cara agar anak dapat mengadopsi cara pandang tersebut.

\section{DAFTAR PUSTAKA}

Achmad, R. (2008). Leukemia, diterima 16 Februari, 2013, dari (http://ridwansyah yusufachmad.com/tentang-leukemia-pada-anak/)

Armitage, J., et al. (2000). Annual of Lymphoid Malignancies. (1 ed). Florida: CRC Press.

Gulö, W. 2002. Metolodogi Penelitian. Jakarta: PT Gramedia Widiasarana Indonesia.

Kementerian Kesehatan Republik Indonesia. (2013). Kanker Penyebab Kematian Keenam Terbesar di Indonesia. Diterima 6 Maret, 2013, dari (http://www.depkes.go.id/ index.php/berita/info-umum-kesehatan/539-kanker-penyebab-kematian-keenamterbesar-di-indonesia.html,.

Kementerian Kesehatan Republik Indonesia. (2013). Jika Tidak Dikendalikan 26 Juta Orang di Dunia Menderita Kanker. Diterima 15 Februari, 2013 dari (http://www.depkes.go.id/ 
index.php/berita/press-release/1060-jika-tidak-dikendalikan-26-juta-orang-di-duniamenderita-kanker-.html.

Kliegman, R., et al. (2011). Nelson Textbook of Pediatrics. 19th edition. Philadelphia: Elsevier Saunders.

Kumar, V., et al. (2009). Robins and Cortan Pathologic Basis of Disease. 8th edition. Philadelphia: Saunders.

Noor, H. (2009). Psikometri, Aplikasi Dalam Penyusunan Instrumen Pengukuran Perilaku. Bandung: Fakultas Psikologi Unisba.

Pizzo, P dan Poplack, D. (1997). Principles and Practice of Pediatric Oncology. 3rd edition. Philadelphia: Lippincott Williams \& Wilkins.

PT Sanofi-Aventis Indonesia. (2007). Onkologi/Kanker. Diterima 6 Maret 2013 dari (http://www.sanofi.co.id///id/in/layout.jsp?scat=535B17A6-FADF-4280-87F9-EE3D 1C8 FD81D)

Rofinda, Z. (2012). Kelainan Hemostasis Pada Leukemia. Andalas Journal of Health. Diterima 22 Mei 2013 dari (http://jurnal.fk.unand.ac.id).

Robianto, T. (2004). Kelainan Leukosit, Leukemia, Myeloma Multipel. Bandung: Bagian PKFK Unpad.

Sari, Y. (2011). Saat Sel Darah Putih Mengganas. Diterima 4 April, 2013 dari (http://posyandu.org/kesehatan/kanker-pada-anak/245-saat-sel-darah-putih-mengganas. html).

Santrock, J. (2006). Life-Span Development. 10th edition. New York: McGraw Hill.

Seligman, M. (2006). Learned Optimism. New York: Pocket Books.

Siegel, S. (1992). Statistik Nonparameterik Untuk Ilmu-Ilmu Sosial. Edisi ke-5. Jakarta: PT Gramedia.

Sudjana. (2005). Metoda Statistika. Bandung: Tarsito.

Tiurma, R. (2008). Buku Ajar Teknik Penulisan Karya Ilmiah. Edisi revisi. Bandung: PT Danamartha Sejahtera Utama.

US Mortality Data. (2006). National Center for Health Statistics. Center for Disease Control and Prevention, 2009.

World Health Organization. (2013). World Cancer Day 2013. Diterima 15 Februari, 2013, dari (http://www.who.int/ cancer/en/ 